Ethos (Jurnal Penelitian dan Pengabdian Masyarakat): 247-252

\title{
Pembuatan Pembersih Lantai (SNI 06-1842-1995) dengan Bahan AKTIF dari EKSTRAK KUlit MANGgis PADA KelompoK WANITA TANi (KWT) Di DESA BARENGKOK BOGOR
}

\author{
THE PRODUCTION OF FLOOR ClEANER (SNI 06-1842-1995) BY ACTIVE MATERIAL FROM \\ MANGOSTEEN FRUIT HULl EXTRACT TOWARD WOMEN FARMER GROUP IN BARENGKOK \\ VILLAGE BOGOR
}

\author{
${ }^{1}$ Linar Humaira, ${ }^{2}$ Srikandi, ${ }^{3}$ Reny Andriyanty \\ ${ }^{1,2,3}$ Program Studi Agribisnis, Fakultas Pertanian, ${ }^{2}$ PS. Biologi F-MIPA Universitas Nusa Bangsa Bogor, \\ Jl. Baru Km.4 Cimanggu, Tanah Sareal, Bogor. \\ e-mail: ${ }^{1}$ linar.humaira@yahoo.com; ${ }^{2}$ sriuus@yahoo.co.id; ${ }^{3}$ reny_andriyanty@yahoo.com
}

\begin{abstract}
The community service based on science and technology (IbM) has done on KWT Rindu Alam and Suka Tani in Barengkok village Leuwiliang Bogor. This programe aimed to increase the skills of exploiting mangosteen fruit hull, that could increase the farmer's income and welfare. The method used counselling, training and assistance. The activitities were: 1) do the counselling about the usage of mangosteen fruit hull, 2) do the training the making of mangosteen fruit hull extracts as according to SNI 06-1842-1995, 3) do the training the distillation in laboratory and also its simplication process, 4) do the making of floor cleaning, 5) the counselling about packaging technique, 6) the training of study business and pricing determination, 7) do the marketing strategy, and 8) do the assistance of production and selling. The output this programme was the floor cleaning with active inggridients of mangosteen fruit hull extract based on SNI 06-1842-1995. The result of this programme increased the female farmer's knowledge and skill of exploiting mangosteen fruit hull. Nowadays they can produce it independently with 120 bottles of floor cleaning $(250 \mathrm{ml}$ capacity) per two weeks or equal with 240 bottles per month. The objection of this programme was reached.
\end{abstract}

Keywords: floor cleaner, mangosteen fruit hull extract.

\begin{abstract}
Abstrak. Iptek bagi Masyarakat ini dilakukan pada KWT Rindu Alam dan KWT Suka Tani di Desa Barengkok Kecamatan Leuwiliang Bogor, dengan tujuan untuk meningkatkan pemahaman dan ketrampilan dalam memanfaatkan kulit manggis, sehingga dapat meningkatkan pendapatan dan kesejahteraan petani manggis. Metode Pelaksanaan Kegiatan menggunakan metode Penyuluhan, Pelatihan dan Pendampingan dengan tahapan kegiatan : 1) Memberikan penyuluhan khasiat kulit manggis secara umum, 2) Pelatihan Proses Pembuatan Ekstrak Kulit Manggis sesuai (SNI 06-1842-1995), 3) Pelatihan Pembuatan Ekstrak Kulit Manggis dengan cara destilasi di Laboratorium, dan dengan cara metode penyederhanaan, 4) Pelatihan Proses Pembuatan Larutan Pembersih Lantai, 5) Penyuluhan Teknik Pengemasan, 6) Pelatihan Analisa Usaha dan Menetapkan Harga Pokok, 7) Penyuluhan Strategi Pemasaran, 8) Pendampingan membuat produk serta memasarkan secara mandiri. Luaran IbM ini adalah produk pembersih lantai dengan bahan aktif dari ekstrak kulit manggis dengan spesifikasi sesuai SNI 061842-1995. Hasil kegiatan IbM ini dapat meningkatkan pemahaman dan ketrampilan wanita tani dalam mengolah kulit manggis. Mereka mampu membuat ekstrak dan produksi cairan pembersih lantai secara mandiri, dengan kapasitas produksi dalam dua minggu menghasilkan 120 botol kemasan $250 \mathrm{ml}$ atau 240 botol per bulan, sehingga target kemampuan untuk meningkatkan pendapatan dan kesejahteraan petani manggis Desa Barengkok telah tercapai.
\end{abstract}

Kata kunci: pembersih lantai, ekstrak kulit manggis 


\section{Pendahuluan}

Berdasarkan rencana induk Bapeda (2005) desa Barengkok adalah desa potensial yang akan diarahkan menjadi Desa Pusat Pertumbuhan (DPP). Potensi utama desa ini adalah sumber daya alam dan budaya yang khas. Di bidang pertanian, desa ini memiliki komoditi yang mampu bersaing dan layak diunggulkan yaitu buah durian dan manggis. Khusus manggis, buah tersebut merupakan komoditas utama yang menjadi unggulan di Kecamatan Leuwiliang. Desa Barengkok sejak tahun 2002 masuk dalam desa pendukung kawasan agropolitan I, dalam Rencana Tata Ruang Wilayah (RTRW) Kabupaten Bogor dalam kawasan komoditas manggis. Desa Barengkok memiliki jumlah penduduk sebanyak 12.854 jiwa dimana 55 persen adalah laki-laki dan 45 persen adalah wanita. Berdasarkan mata pencaharian masyarakatnya, sebagian besar penduduk berprofesi sebagai petani dan buruh tani. Secara lebih jelas mata pencaharian dan persentase masyarakat Desa Barengkok tertera pada tabel berikut.

Tabel 1. Jenis pekerjaan dan persentase masyarakat Desa Barengkok.

\begin{tabular}{c|c}
\hline Jenis Pekerjaan & Persentase \\
\hline Petani dan Buruh Tani & $40 \%$ \\
\hline Pedagang & $25 \%$ \\
\hline Swasta & $15 \%$ \\
\hline Sopir & $10 \%$ \\
\hline Buruh Pabrik & $10 \%$ \\
\hline
\end{tabular}

Sumber: Monografi Desa Barengkok, 2013.

Besarnya penduduk Desa Barengkok yang berusaha sebagai petani dan buruh tani serta besarnya persentase penduduk wanita, yang diataranya terdapat dua kelompok wanita tani yaitu KWT Rindu Alam dan KWT Suka Tani, maka perlu dilakukan upaya pemberdayaan terhadap kelompok wanita taninya. Peningkatan produktivitas tenaga kerja disektor perkebunan manggis yang banyak diusahatanikan di desa ini menjadi upaya penting. Karena peningkatan produktivitas kelompok tani ini akan meningkatkan pendapatan dan kesejahteraan penduduk Desa Barengkok.

Usahatani manggis yang dibudidayakan di Desa Barengkok hanya dipanen dan dijual dalam bentuk primer. Selama ini, yang dinikmati dari buah manggis adalah daging buahnya saja, sementara kulitnya dibuang. Saat ini banyak penelitian yang membuktikan bahwa kulit buah manggis yang memiliki banyak manfaat bagi kesehatan. Penelitian Azzahra, Pujiastuti dan Purwanto (2014) menyatakan bahwa ekstrak kulit buah manggis dapat meningkatkan aktivitas mikrobisidal sel neutrofil yang dipapar $S$. mutans. Berdasarkan penelitian Ni'maa, Subakir dan Suhardjono (2011) disebutkan bahwa ekstrak kulit buah manggis (Garcinia mangostana Linn) 100\% sebanding dengan ketokonazol $2 \%$ dalam menghambat pertumbuhan P.ovale. pada ketombe secara in vitro. Penelitian Nugroho 2014, menunjukkan bahwa ekstrak kulit buah manggis dan senyawa aktifnya memiliki aktivitas farmakologi yaitu anti-alergi, antiinflamasi, anti-oksidan, anti-kanker, antimikroorganisme, anti-aterosklerosis, dan bahkan anti-HIV. Pada uji toksistas, ekstrak etanol buah manggis yang mengandung senyawa aktif xanton tidak menunjukkan toksisitas baik secara akut maupun subkronis. Sementara Srikandi (2014) menyatakan bahwa ekstrak kulit manggis dengan etil asetat memberikan kadar hambatan minimal (KHM) rata-rata terhadap pertumbuhan 
Staphylococcus aureus ATCC 25923 adalah $125 \mathrm{mg} / \mathrm{ml}$, dan P.aeuroginosa ATCC 27853 adalah $500 \mathrm{mg} / \mathrm{ml}$, dan diameter zona hambatan juga terdapat pada semua konsentrasi. Dalam mengamati nilai KHM terlihat adanya perbedaan antara KHM bakteri Staphylococcusaureus ATCC 25923 dan P.aeuroginosa ATCC 27853. Hal ini disebabkan karena perbedaan sensitivitas masing-masing bakteri.

Persoalan yang dihadapi di Desa barengkok adalah tersedia banyak kulit manggis karena memang desa ini penghasil buah manggis utama di Kecamatan Leuwiliang. Namun masyarakatnya belum bisa memanfaatkan kulit manggis menjadi bahan yang memiliki nilai jual. Oleh sebab itu solusi yang ditawarkan untuk permasalahan tersebut adalah melalui kegiatan program Iptek bagi Masyarakat untuk Desa Barengkok yaitu pembuatan cairan pembersih lantai dengan bahan dasar ekstrak kulit manggis sebagai bahan aktifnya. Pembuatan cairan pembersih dengan bahan dasar ekstrak kulit manggis apabila dilakukan di laboratorium akan lebih efisien, namun bagi petani akan riskan bila harus menggunakan berbagai alat dan bahan kimia. Terkait hal tersebut, perlu memodifikasi teknik dan prosedurnya agar lebih sederhana. Tujuan dari kegiatan ini adalah untuk meningkatkan pemahaman dan ketrampilan Kelompok Wanita Tani dalam mengolah kulit manggis. Sehingga diharapkan setelah mereka mampu membuat ekstrak kulit manggis dan cairan pembersih lantai ini secara mandiri, akan terjadi peningkatan pendapatan dan kesejahteraan petani manggis. Pemecahan masalah yang ditawarkan melalui kegiatan penyuluhan, pelatihan dan pendampingan pembuatan produk cairan pembersih lantai dengan bahan aktif dari ekstrak kulit manggis dengan spesifikasi sesuai SNI 06-1842-1995. Jenis luaran yang dihasilkan adalah berupa Produk cairan pembersih lantai.

\section{Metode Pelaksanaan Kegiatan}

Metode pelaksanaan kegiatan yang dilakukan dalam program IbM ini adalah berupa penyuluhan, pelatihan, dan pendampingan pembuatan ekstrak dan cairan pembersih lantai dengan bahan aktif dari ekstrak kulit manggis pada kelompok wanita tani mitra yaitu Kelompok Wanita Tani Rindu Alam dan Kelompok wanita tani Suka Tani di Desa Barengkok, kecamatan Leuwiliang Bogor.

Bahan dan alat utama yang digunakan adalah: Kulit manggis segar dan Methanol untuk membuat ekstrak kulit manggis; Bahan untuk membuat larutan pembersih lantai adalah: Ekstrak kulit manggis, CMC, Texapon, Propilen Glikol dan Air/Aquadest. Alat-alat utama yang digunakan: Pisau, oven, blender, tempat perendaman, saringan, Evavorator dan Waterbath.

Teknis pelaksanaan kegiatannya sebelum dan sesudah pelaksanaan kegiatan dilakukan penyebaran kuesioner, untuk menetapkan metode penyuluhan serta melihat tingkat keberhsilan dari kegiatan. Tahapan kegiatannya 1) Memberikan penyuluhan khasiat kulit manggis secara umum, 2) Pelatihan Proses Pembuatan Ekstrak Kulit Manggis sesuai (SNI 06-1842-1995), 3) Pelatihan Pembuatan Ekstrak Kulit Manggis dengan cara destilasi di Laboratorium, dan dengan cara metode penyederhanaan, 4) Pelatihan Proses Pembuatan Larutan Pembersih Lantai, 5) Penyuluhan Teknik Pengemasan, 6) Pelatihan Analisa Usaha dan Penentuan Harga Pokok, 7) Penyuluhan Strategi Pemasaran, 8) Pendampingan membuat produk serta memasarkan secara mandiri. 


\section{Hasil dan Pembahasan}

\subsection{Hasil yang dicapai}

Kegiatan program IbM yang dilaksanakan dengan metode penyuluhan, pelatihan dan pendampingan melalui tatap muka dan ceramah dilanjutkan dengan praktek dihasilkan sangat efektif, ini terlihat dari antusiasnya mitra dalam mengikuti kegiatan IbM ini. Kegiatan ini dilakukan pada dua mitra yaitu KWT Suka Tani dan KWT Rindu Alam dengan jumlah perserta 20 orang. Dari hasil angket pra pelatihan rata-rata umur peserta/mitra berumur 38 tahun dengan pendidikan rata-rata SMP. Dari hasil angket pra pelatihan tersebut sebagai dasar untuk menetapkan metode penyuluhan dan pelatihan serta menetapkan modul/ materi yang akan disampaikan sehingga mudah dipahami oleh mitra. Karena keberhasilan menggunakan metode penyuluhan yang perlu dipertimbangkan adalah melihat karakteristik sasaran penyuluh, karakteristik penyuluh, karakteristik keadaan daerah, materi penyuluhan, sarana dan biaya, dan kebijakan pemerintah (april.blogspot.com/2013/09/metode-dan-teknik-penyuluhan-pertanian.html, diakses 29 Agustus 2016).

Peserta/mitra sangat antusias mengikuti kegiatan IbM ini karena dari hasil angket pun mitra belum pernah mendapatkan materi kegiatan yang sejenis. Pada umumnya sebanyak $73 \%$ dari anggota mitra/peserta mengetahui manfaat dari kulit manggis, namun mereka hanya mengetahui manfaat kulit manggis sebatas dijadikan sebagai obat herbal yang dikeringkan secara penjemuran saja. Sehingga peserta sangat antusias dalam mengikuti kegiatan Iptek bagi Masyarakat ini.

Kegiatan yang diawali dengan metode penyuluhan terlebih dahulu untuk memberikan pemahaman secara teoritis manfaat kulit manggis secara umum yang kemudian dilanjutkan dengan kegiatan pelatihan, sampai peserta mampu untuk membuatnya secara mandiri. Di sesi terakhir untuk melihat tingkat kepuasan peserta pelatihan disebarkan kuesioner/angket kepada peserta. Hasil dari kegiatan ini menurut peserta adalah telah berhasil memberikan pengetahuan dan ketrampilan bagi peserta, ini dapat dilihat dari score hasil angket pasca kegiatan pelatihan yang menunjukkan score berada pada rata-rata kisaran 4.2 - 4.7 yang dapat disimpulkan bahwa peserta merasa puas sampai sangat puas dari hasil materi kegiatan IbM ini.

Evaluasi kegiatan IbM yang dilakukan melalui pendampingan kepada peserta pelatihan untuk dapat membuat cairan pembersih lantai dan memasarkannya secara mandiri, bahwa dalam selang waktu dua minggu setelah kegiatan IbM ini mitra sudah mampu memasarkan produk pembersih lantai. Mereka sudah mampu membuat kemasan dan label atau merek dagang sendiri. Kemudian mereka sudah mampu memproduksi sebanyak 120 botol dalam tempo dua minggu, atau kapasitas produksi dalam sebulan 240 botol kemasan $250 \mathrm{ml}$ dengan dengan nilai jual Rp. 1.680.000,- per bulan. Dengan demikian hasil dari kegiatan IbM ini dapat meningkatkan pemahaman dan kemampuan serta ketrampilan peserta dalam meningkatkan pendapatan dan kesejahteraan petani manggis di desa Barengkok.

\subsection{Luaran yang dicapai}

Luaran yang telah dicapai dari kegiatan Iptek bagi Masyarakat ini adalah:

1. Produk Pembersih Lantai sesuai dengan SNI 06-1842-1995, dengan merek G.M.B Clean dalam berbagai kemasan yaitu $250 \mathrm{ml}, 500 \mathrm{ml}, 1000 \mathrm{ml}$ dan 2.5 liter. Produk ini sudah sesuai dengan ketentuan standard national Indonesian 
yaitu berisi syarat mutu, cara uji dan cara pengemasan cairan desinfektan pembersih lantai.

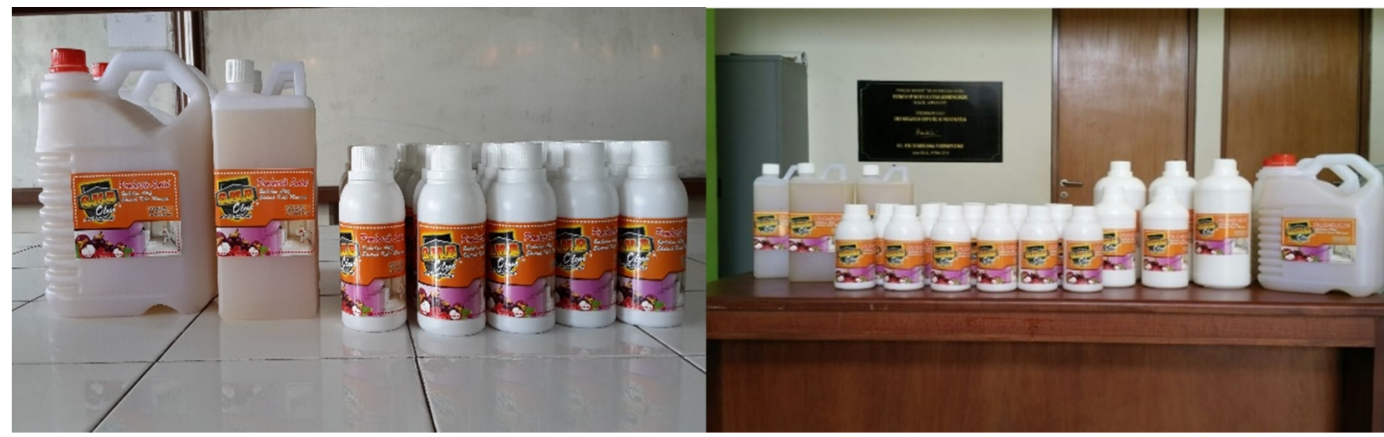

Gambar 1. Foto Luaran Produk Pembersih Lantai

2. Dari hasil pendampingan selama program ini, terlihat adanya peningkatan pemahaman dan ketrampilan masyarakat tani maggis di Desa Barengkok serta dapat meningkatkan pendapatan dan kesejahteraan wanita tani secara mandiri. Hal ini dapat dibuktikan dari kemampuan mitra dalam berproduksi pembersih lantai berbahan aktif ekstrak kulit manggis dengan kapasitas produksi 120 botol kemasan $250 \mathrm{ml}$ dalam dua minggu (atau 240 botol dalam sebulan), dengan menggunakan labeling dan kemasan secara mandiri.

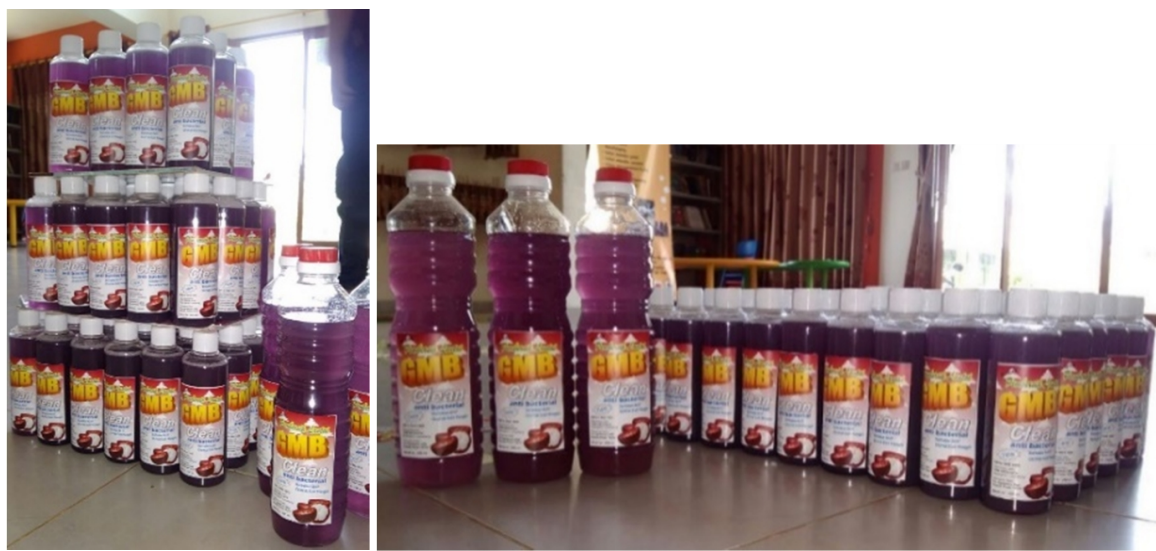

\section{Gambar 2 : Produk yang Dihasilkan Mitra Secara Mandiri Setelah Kegiatan IbM.}

\section{Kesimpulan}

Berdasarkan hasil Kegiatan IbM ini dapat disimpulkan bahwa kegiatan pelatihan pembuatan pembersih lantai dari ekstrak kulit manggis ini dapat meningkatkan pemahaman dan ketrampilan anggota KWT Rindu Alam dan KWT Suka Tani di Desa Barengkok dalam mengolah kulit manggis. Selain itu sudah mampu membuat ekstrak dan cairan pembersih lantai serta mampu memproduksi dan memasarkan produknya secara mandiri. Kemampuan mitra berproduksi sebanyak 240 botol kemasan $250 \mathrm{ml}$ per bulan, sehingga target yang diharapkan telah tercapai yaitu KWT manggis di Desa Barengkok mampu meningkatkan pendapatan dan kesejahteraannya.

Luaran pelatihan ini adalah produk cairan pembersih lantai berbahan akktif dari ekstrak manggis dengan spesifikasi sesuai SNI 06-1842-1995. Standar ini berisi syarat mutu, cara uji dan cara pengemasan cairan desinfektan pembersih lantai.

Berdasarkan kesimpulan diatas, bahwa kegiatan IbM ini perlu dilanjutkan ke tahap berikutnya yaitu melalui kegiatan-kegiatan lainnya dalam memafaatkan baik dari 
kulit manggis maupun dari daging buah manggisnya, sehingga peningkatan pendapatan dan kesejahteraan petani manggis bisa terpadu dan berkelanjutan.

\section{Ucapan Terima Kasih}

Penulis mengucapkan terima kasih kepada Direktur Riset dan Pengabdian Masyarakat Direktorat Jenderal Penguatan Riset dan Pengembangan Kementerian Riset, Teknologi dan Pendidikan Tinggi yang telah berkontribusi membantu pendanaan Pelaksanaan Pengabdian Masyarakat (Iptek bagi Masyarakat) ini sampai kepada publikasi jurnal.

\section{Daftar pustaka}

Azzahra, Hamidah., Peni Pujiastuti dan Purwanto. 2014. Potensi Ekstrak Kulit Buah

Manggis (Garcinia mangostana L.) Buatan Pabrik Terhadap Peningkatan Aktivitas

Mikrobisidal Sel Neutrofil yang Dipapar Streptococcus mutans. e-Jurnal Pustaka

Kesehatan, vol. 2 (no 1.). p:161-166, Januari 2014. Universitas Jember. Jember.

april.blogspot.com/2013/09/metode-dan-teknik-penyuluhan-pertanian.html, diakses 29

Agustus 2016

BPS. 2011. Laporan Bulanan Data Sosial Ekonomi. Katalog BPS Edisi 31. Desember

2011. Jakarta.

https://munalakanti.wordpress.com/category/metode-dan-teknik-penyuluhan-pertanian,

diakses 29 Agustus 2016

http://www.agrina-online.com

http://www.kotabogor.go.id

Monografi Desa Barengkok. 2013. Bogor.

Ni'maa, Dahlia Kahirun., Subakir dan Suhardjono. 2011. Perbandingan Ekstrak Kulit

Buah Manggis (Garcinia mangostana Linn) dengan Ketokonazole 2\% dalam

Menghambat Pertumbuhan Pityrosporum Ovale pada Ketombe. Skripsi pada

Fakultas Kedokteran Universitas Diponegoro. Semarang.

Nugroho, Agung Endro. 2014. Manggis (Garcinia mangostana L.) : Dari Kulit Buah

yang Terbuang Hingga Menjadi Kandidat suatu Obat. Skripsi pada Bagian

Farmakologi dan Farmasi Klinik, Fakultas Farmasi, Universitas Gadjah Mada. Yogyakarta. 